\title{
Princípios Fundamentais para o Ensino e a Aprendizagem do inglês como língua Global
}

Flavius Almeida dos Anjos flaviusanjos@gmail.com Universidade Federal do Recôncavo da Bahia, Brasil.

\begin{abstract}
RESUMO
Este artigo propõe refletir sobre princípios fundamentais para o ensino e a aprendizagem do inglês como língua global. Busca, na perspectiva da era pós-colonial e, à luz da Linguística Aplicada, articular o dialogo com autores (BOAVENTURA DE SOUSA SANTOS, 2009; PENNYCOOK, 2000; KUMARAVADIVELU, 2012; RAJAGOPALAN, 2003, 2009 e GROSFOGUEL, 2009) cujas ideias convergem para a descolonização do conhecimento. Ancorado na Pedagogia Crítica e levando em consideração o status global da língua inglesa, este trabalho pavimenta o caminho para a discussão sobre problemas que enfrentam a educação básica e superior, quando ainda relegam a um segundo plano o ensino da língua inglesa, a mercê de políticas linguísticas frágeis. A discussão é ampliada para, por fim, trazer em seu bojo proposta de descolonização da língua inglesa, adotando pedagogias críticas que possibilitem emancipar os aprendizes para que possam usar esse idioma global com autonomia e livres das amarras das ideologias colonialistas que limitam o pensamento e inferiorizam povos e culturas, o que poderá acontecer com o uso de princípios que orientem docentes à consolidação de aprendizagens significativas.
\end{abstract}

PALAVRAS-CHAVE: Ensino/aprendizagem. Princípios. Descolonização. Língua inglesa. 


\section{INTRODUÇÃO}

Este trabalho está essencialmente fundamentando numa perspectiva póscolonial, já que entende este momento sócio-histórico como palco para críticas ao desenvolvimento das formas etnocêntricas de conhecimento, que reproduzem hierarquias e desigualdades e, assim, se posiciona. Vejo o póscolonial como momento, mas também como movimento epistemológico que reage e produz contradiscursos frente às investidas colonialistas que ainda se manifestam na modernidade-mundo. No âmbito do ensino/aprendizagem da língua inglesa, o pós-colonial emerge como movimento questionador da adoção de metodologias e abordagens, livros didáticos, da supremacia do falante nativo, da imposição dos acentos nativos, do conceito de erro, quando falantes de outras línguas usam o inglês em situações sociocomunicativas.

Este artigo desenvolve-se ancorado nesta perspectiva, pois apresenta-se como alternativa para tomada de consciência crítica por parte de docentes e sugere, sob a égide da Linguística Aplicada, meios de combater e superar complexos que hierarquizam povos, culturas e línguas. A intenção é alertar docentes com relação à necessidade da adoção de princípios que norteiem o ensino/aprendizagem de uma língua global, o que promoverá a descolonização do saber. Para tanto, faz-se necessário adotar uma nova linguagem descolonial, o que só ocorrerá com o abandono de paradigmas, abordagens, disciplinas e campos. (GROSFOGUEL, 2009)

Nas próximas linhas, descrevo brevemente o cenário atual contemporâneo, destaco o status que a língua inglesa assume neste momento sócio-histórico, para, então problematizar o ensino desse idioma no contexto nacional, na educação básica e superior. Ainda, apresento princípios para a educação docente de uma língua global, alinhando com reflexão acerca da ideologia colonialista ainda presente em muitas de nossas salas de aula de língua inglesa e propor, por fim, a descolonização do conhecimento, como reação transmoderna descolonial ao processo de colonização etnocêntrica, visando superá-lo através de mais um 'pensamento crítico de fronteira'. (MIGNOLO 2000 apud GROSFOGUEL, 2009).

\section{O CENÁRIO PÓS-COLONIAL E O INGLÊS COMO LÍNGUA GLOBAL}

Esta é uma era marcada pela tecnologia, instabilidade econômica, política e moral. Momento em que as identidades estão sendo redefinidas e as barreiras territoriais encurtadas pelo avanço dos meios de comunicação. Momento em que vivenciamos crises políticas e abalo aos dogmas, nas mais diversas instituições públicas e privadas, nacionais e internacionais. Neste mesmo cenário é que uma língua, com características tanto global quanto (ainda) colônial opera: a língua inglesa. Para Graddol (2006), após o Old English, o Middle English e o Modern English, estamos vivenciando o quarto período da língua inglesa: o Inglês como língua Global (ILG), com implicações políticas, econômicas, culturais e linguísticas em âmbito mundial. 
Inegável o papel que a língua inglesa assume na contemporaneidade, cujo status de língua global evidencia a necessidade de aprender esse idioma, com os mais variados fins, quer seja acadêmico, profissional ou integrativo'. Essa língua global já consegue um grande número de adeptos, falantes de outras línguas. Isso tem ocorrido por necessidades particulares individuais ou profissionais, ou por acreditar no sucesso desaforado desse idioma, por conseguir penetrar na vida científica, econômica e industrial. (LACOSTE, 2005) Tal cenário, onde a língua inglesa alastra-se, cujo início tem forte ligação com os impérios Britânico e Americano, tornou-se possível, também, graças a uma relação simbiótica entre a língua inglesa, a internet e o fenômeno da globalização, como bem destaca Mydans (2007, p. 1):

Ter uma língua global tem auxiliado a globalização, e a globalização tem consolidado a língua global. Esse processo começou com o domínio dos dois impérios de fala inglesa, que se sucederam, o Britânico e o Americano, e continua hoje com o novo império virtual da Internet ${ }^{2}$.

Esse processo de desterritorialização da língua inglesa fazia parte do projeto de colonização da Inglaterra e o seu status de língua global resultou também da expansão do poder colonial Britânico e do surgimento dos Estados Unidos como liderança econômica. (CRYSTAL, 2012) Tal surgimento fortaleceu a disseminação da noção equivocada do etnocentrismo, ao colocar essas duas nações, suas línguas e culturas, em nível de superioridade, as quais devem ser emuladas, por conta dos seus supostos padrões de excelência em diversas áreas. Essa noção supostamente sinalizava que, ao orientar-se por esses caminhos, seria possível igualar-se ao colonizador. Mas era apenas um pensamento, já que o sistema colonial obteria êxito a partir do momento em que sujeitos socialmente situados do lado oprimido, fossem levados a pensar epistemicamente como aqueles que se encontram em posições dominantes. (GROSFOGUEL, 2009) Por conta disso, também era (e ainda é em alguns contextos) excessivamente incentivada e seguida à risca (quando não imposta) a aprendizagem dos acentos do inglês falado nos Estados Unidos e na Inglaterra, provando que ainda a relação colonialismo e ensino da língua inglesa continua viva. (PENNYCOOK, 2006) No entanto, curiosamente, parece haver uma tomada de consciência crítica por parte dos aprendizes e docentes, porque eles têm se apropriado, reentoado e ressignificado a língua inglesa. (ASSIS-COX, PETERSON, 2007)

Ainda em fase de progressão, que de nacional tornou-se universal, a língua inglesa tem se consolidado como instrumento de acesso ao saber, alicerçando profundamente o conhecimento no campo das ciências puras, aplicadas e tecnológicas, cuja universalidade acaba por atrair um grande número de adeptos, em busca do progresso. Quanto a isso, Lacoste $(2005$, p. 21$)$ assegura que:

De língua nacional, ele [o inglês] se tornou imperial e tende a tornarse universal, e não apenas por uma questão de geografia. Ele aspira manifestamente a se tornar a língua do progresso, da ciência, da pesquisa; a língua da inovação, da conquista material; a língua da riqueza, a língua dos homens que são seguros de si e que podem ser tomados como modelo, sem deixar de ser a língua do não 
conformismo e da liberdade de espírito. Essa é a nova fase da progressão do inglês.

Essa nova fase, a qual Lacoste faz referência, coloca, de certa forma, em evidência o próprio papel de um idioma global. Crystal (2012), quanto a isso, diz que uma língua global é aquela que tem um papel especial reconhecido em diversos países. Uma língua se torna global quando outros países, que não sejam os do círculo interno (EUA, Inglaterra, Austrália, Canadá, Nova Zelândia) decidam usá-la, conferindo-lhe um lugar especial em suas comunidades. Grosso modo, uma língua global não está presa a uma cultura $A$ ou $B$, mas ela serve a comunidades que reconheçam a sua relevância. Sobre isso, Rajagopalan (2009) coloca que, há um bom tempo, o inglês deixou de ser propriedade dessa ou daquela nação, desse ou daquele país. Nesse sentido, este autor tem chamado atenção para o que ele convencionou chamar de World English, um fenômeno linguístico híbrido que tem tomado conta do mundo inteiro. Vejam como ele define esse fenômeno:

\begin{abstract}
A língua inglesa hoje é uma língua proteiforme. O que "rola" no mundo afora hoje em dia é algo que costumo chamar de "World English", onde falares e sotaques diferentes (que muitos chamam de "World Englishes", no plural), convivem e, por vezes, se digladiam entre si. Essa língua não tem pátria, nem está delimitada a uma região geográfica. É esse novo fenômeno linguístico que devemos nos esforçar para ensinar e aprender, porque é dele que os aprendizes de hoje vão precisar no futuro bem próximo. (RAJAGOPALAN, K. 2011, p.65).
\end{abstract}

O World English é uma modalidade linguística que não se restringe aos falantes nativos, mas pertence a todos que a utilizam diariamente, por mais limitado e restrito que esse uso seja, como acessar a internet, ler manuais de instrução, ouvir uma música etc. Uma língua sem donos, global, de todos. Por que esse idioma global é também a principal língua da mídia, dos jornais, da publicidade, da economia, do marketing, dos filmes, dos desenhos, dos congressos, da ciência e da integração entre povos. Por isso, é indiscutível o papel desse idioma na sociedade mundial e a 'hegemonia total, e de certa forma, assustadora no mundo em que vivemos'. (RAJAGOPALAN, 2010, p. 21) Diante do papel que a língua inglesa representa hoje para diversas nações, é relevante provocar discussão em torno do ensino e da aprendizagem desse idioma, o que farei na seção seguinte.

\title{
2. O ENSINO DA LÍNGUA INGLESA NO BRASIL: O DESCASO, IDEOLOGIA COLONIALISTA E O QUE SE ESPERA DO PROFESSOR
}

Pelas razões anteriormente expostas, diversas nações já adotaram políticas linguísticas com vistas a fomentar o desenvolvimento do ensino do inglês. No entanto, alguns desses países ainda não conseguiram acertas os passos no que diz respeito à oferta de um ensino/aprendizagem que contemplem aprendizes com formação adequada. O Brasil, por exemplo, ainda adota uma velha prática mecânica de inculcação de compêndios gramaticais no seu sistema regular de 
ensino. Tradicionalmente, este ensino, em muitos casos, tem se revelado muito doloroso, tendo em vista fomenta a prática mecânica de exercícios de análise sintática por meio de frases descontextualizadas. (BAGNO, 2002) Configura-se ledo engano achar que o ensino de uma língua estrangeira pode ou deve ser conduzido com base em concepções estruturalistas de língua apenas. Muitas escolas prosseguem ainda nesse percurso, sem resultados satisfatórios, porque ainda permitem, a mercê de políticas linguísticas frágeis, um ensino de carga horária ínfima, de duas horas semanais apenas, calcado exclusivamente em compêndios gramaticais. Como consequência disso, não sem razão, as escolas regulares brasileiras, sobretudo as públicas, tem formado uma geração de aprendizes com pouca ou nenhuma habilidade em uma LE.

Esse cenário sinaliza descaso com as línguas estrangeiras, que não limita-se à educação básica, alcança a superior, onde a carga horária chega a ser inferior a duas horas semanais. A respeito disso, os Bacharelados Interdisciplinares da Universidade Federal do Recôncavo da Bahia, ofertados nos diferentes centros, incluem nas suas matrizes curriculares a língua inglesa, com carga horária presencial de uma hora semanal. Por conta disso, limita-se, desse modo, a possibilidade de um ensino/aprendizagem de uma LE transformadores, que realmente preparem aprendizes para agir em cenários diversos, possibilitando acesso a novas formas de ser, agir e pensar, mediados pela língua estrangeira, em vez de se preocuparem com estruturas meramente gramaticais. O que, de fato, não tem ocorrido em diversos contextos de aprendizagem. Por isso, é possível afirmar que, na verdade, o objetivo a ser alcançado com a aprendizagem da LE ainda está mal compreendido. Nessa linha de pensamento, Kumaravadivelu (2012, p. 28) nos diz que:

Uma língua é melhor aprendida quando o foco não está na língua, quando a atenção dos aprendizes está focada em compreender, dizer e fazer algo com a língua, mesmo se eles não estão explicitamente preocupados com as propriedades formais.

A realidade nas escolas regulares é bem diferente da proposta de Kumaravadivelu (2012), alinha-se com metodologias que fomentam práticas mecânicas de estruturas gramaticais, desconsiderando nuances da vida em sociedade, que muito bem podem ser problematizadas, através da LE. Além disso, destaco a maneira colonizadora como ainda muitas aulas de língua inglesa são conduzidas, com base nas culturas hegemônicas. Isso, por sua vez, tem corroborado a ideologia neocolonialista, de veneração desmedida do nativo (RAJAGOPALAN, 2003), bem como a ideologia da língua padrão "standard language ideology", já que ensino da língua inglesa historicamente tem sido centrado nas variedades do inglês faladas no círculo interno. Tal viés de ensino tem favorecido a configuração de um linguicismo (CANAGARAJAH, BEN SAID, 2011), quando, com base nessa ideologia, acaba promovendo atitudes discriminatórias em relação às outras variedades do inglês, ao conferir exclusividade do ensino das variantes hegemônicas, conforme nos revela Schimtz (2016, p. 359):

No início a presença do inglês britânico dominava, mas depois da Segunda Guerra Mundial, o inglês estadunidense se tornou mais 
presente no cenário de ensino brasileiro. Os centros-binacionais do Reino Unido e dos Estados Unidos têm por alvo o ensino das respectivas variedades das duas nações junto com a divulgação das culturas britânica e americana. A metodologia utilizada nos institutos foi influenciada pelo estruturalismo, o método áudiolingual e mais tarde pela abordagem comunicativa e sua política de "English only".

Por conta desse cenário marcado por ideologias colonialistas, reveladores de um descaso político, que, sobretudo, nas escolas regulares, também revela problemas de metodologias, de carga horária, do grande número de alunos por turma, com o livro didático, da escassez de recursos tecnológicos, os quais podem impedir o êxito das aulas de língua inglesa, é urgente a necessidade do estabelecimento de princípios que realmente possam nortear o ensino/aprendizagem da língua inglesa, com vistas também a promover a descolonização do conhecimento. O conhecimento colonizado na sala de aula de língua inglesa impera quando professores e aprendizes emulam a cultura alvo, quando deixam de ser eles mesmos e identificam-se plenamente com o colonizador, dando margem à imitação do colonizador em todos os níveis, corroborando a sua superioridade (MOITA LOPES, 1996), e fomentando o que Scheyerl (2012) chamou de 'mito da mímese' ou do 'colonizador', para se referir ao micromundo posto no livro didático de língua estrangeira, onde o mundo das culturas alvo é o ideal, quando impõe, através de suas páginas, o mundo branco e anglo-saxônico, ao conceber suas línguas, culturas e estruturas políticas como avançadas, modernas, civilizadas, masculinas e maduras (ANJOS, 2013). Isso por sua vez acaba por favorecer o surgimento de uma sociedade alienada, baseada na imitação servil de outras culturas. (FREIRE, 1979)

A respeito disso, por exemplo, é que processos socioculturais de consumo de comida rápida proliferam-se em diversas partes do mundo, delineando-se como o que Ritzer cunhou de 'MacDonaldinazação', legitimando a noção de que os discursos do colonialismo reproduzem também relações materiais do colonialismo (PENNYCOOK, 1998), atendendo aos interesses, obviamente, do colonizador. Tal processo também acaba por incentivar uma exaltação aos modos de ser e produzir estrangeiros, fomentando a noção de modelos perfeitos no que diz respeito à moda, à música, à tecnologia. Isso, em certa medida, contribui para o desencadeamento de atitudes alienadas, bem como para silenciar a própria cultura do aprendiz, porque no contexto colonial os conhecimentos populares, leigos, camponeses e indígenas são silenciados e desaparecem como saberes relevantes. (SOUSA SANTOS, 2009)

Esse desaparecimento (omissão) encontra guarida em muitos livros didáticos de língua inglesa, para fortalecer essa empreitada colonizadora, porque, por excelência, muitos livros didáticos são reprodutores de ideologias em favor do conhecimento colonizador. Assim, por exemplo, caberia questionar muitos autores e editores dos livros didáticos onde estão os problemas sociais, as mazelas, a fome, a intolerância e a corrupção? A que espaços ficam destinados os conflitos, as guerras, a favela, as políticas públicas, questões de gênero, raça e etc? (ANJOS, 2017) É o império da presença das ausências. Quanto a isso, Anjos (2017, 48-49) destaca que: 
É assim é que em tais contextos, muitos não se reconhecem, não se identificam, sobretudo os aprendizes das classes minoritárias, os excluídos, os portadores de alguma necessidade especial, dentre outros cidadãos e cidadãs, que por terem as suas origens e causas nada interessantes ou rentáveis aos olhos de editores e autores, acabam sendo excluídos, 'atropelados' por uma ideologia nefasta.

Como se vê no excerto acima, de maneira furtiva e silenciosa, a ideologia colonialista manifesta-se nas páginas dos livros didáticos de língua inglesa, para subverter realidades, já que muitos livros didáticos de língua inglesa optam por omitir questões das culturas minoritárias e reproduzem modos de ser, agir e pensar das hegemônicas, favorecendo o desencadeamento do que Anjos (2013) convencionou chamar de 'atitudes de supervalorização em relação à língua e à cultura estrangeira'.

Nessa perspectiva é que tenho defendido a necessidade de adoção de atitudes que desconstruam o pensamento colonialista, que descolonizem o conhecimento, porque o pensamento e práticas ocidentais de exclusão social, semelhantemente às do ciclo colonial, ainda permanecem. (SOUSA SANTOS, 2009) E no caso do ensino e aprendizagem da língua inglesa, suponho que esse pensamento colonialista contribui para alicerçar atitudes acríticas e excludentes. Por isso que no cerne desta questão está o professor de língua inglesa, o qual precisa ter atitudes críticas frente ao processo de ensino/aprendizagem, porque ele, de fato, deve ter uma postura responsável na formação dos propósitos e condições de escolarização. (cf. GIROUX, 1997) É ele quem vai orientar em sala de aula quanto às ideologias presentes nos diversos textos que circulam na sociedade, que constroem as relações, pois como bem salienta Pennycook (1998), as salas são espaços sociais em si mesmas, onde emergem temáticas como democracia e relações de poder, além de uma preocupação com a igualdade social nas relações de ensino-aprendizagem. Desse modo, o professor precisa de princípios que os conduzam a atmosferas propícias de ensino e aprendizagem e que os possibilitem vencer as limitações que lhes são impostas, quer por questões de políticas linguísticas ou ideológicas. Por isso, mais do que urgente é a necessidade de se repensar princípios que possam nortear o ensino e a aprendizagem da língua inglesa. Nas próximas linhas, discorro sobre a contribuição de Kumaravadivelu (2012) nesse sentido, o qual postula três princípios para a formação do professor de línguas na sociedade global.

\section{PRINCÍPIOS FUNDAMENTAIS PARA A FORMAÇÃO DO PROFESSOR DE LÍNGUA INGLESA NA SOCIEDADE GLOBAL}

Na contemporaneidade, a língua inglesa atinge um nível que possibilita ensiná-la e aprendê-la desatrelada de suas raízes iniciais, não havendo a suposta necessidade da custódia dos falantes nativos. Ensinar uma língua global requer pensá-la em condições locais, com possibilidade de manutenção da identidade do aprendiz. Ensinar um idioma global requer, de fato, a elaboração de princípios capazes de orientar o docente, direcionando-o a práticas que cada vez mais 
contribuam para a consolidação de aprendizagens significativas. No âmago dessa reflexão, em perspectivas pós-coloniais, Kumaravadivelu (2012) propõe três parâmetros que podem funcionar como princípios para a educação do professor de língua inglesa. Para Kumaravadivelu esses princípios apresentam potencial para contextualizar imperativos de ordem política, social, cultural do processo de ensino e aprendizagem de línguas. Esse autor propõe três princípios que interagem entre si numa relação de sinergia, a saber: 1 . Particularidade; 2. Praticidade; 3 . Possibilidade, sobre os quais discorro nas linhas que se seguem.

\subsection{PRINCÍPIO 1: DA PARTICULARIDADE}

Kumaravadivelu (2012) fundamenta o princípio Particularidade na noção de que uma pedagogia significativa deve ser formulada com base numa compreensão holística da situação de ensino e aprendizagem. Esse autor acredita ser necessária a sensibilidade a uma série de questões para a consolidação do ensino e da aprendizagem significativos. Para tanto, ele sinaliza ser preciso levar em consideração o grupo de aprendizes, os contextos locais, institucionais, sociais e culturais em que ocorrem os processos de ensino e aprendizagem; as necessidades dos aprendizes, o que, ao não ser levado em consideração, logo tornará o processo ineficiente e irrelevante. (KUMARAVADIVELU, 2012) Pensamento semelhante é encontrado nas ideias de Richards e Rodgers (2014), ao verificar que esses autores acreditam que os professores devem adaptar os métodos de ensino/aprendizagem de acordo com os seus contextos, numa perspectiva local, levando em consideração crenças e estilos de ensino, o tamanho do grupo, o nível de proficiência, a idade, a bagagem cultural e as necessidades dos aprendizes, bem como os objetivos com o aprendizado da língua. Quanto a isso, Richards (2014) sinaliza alguns fatores limitantes da aprendizagem da língua inglesa, tais como: o grande número de alunos, com turmas que chegam a 50 alunos ou mais, dificultando a ocorrência de oportunidades para o uso autêntico da língua, a carga horária limitada, de poucas horas semanais, bem como materiais didáticos e currículos inadequados.

Tais fatores acabam produzindo, em alguns contextos, formados por agentes críticos, resistência; como é o caso do Sri Lanka, que resistiu frente à metodologia imposta do uso exclusivo do inglês, para fortalecer as culturas ocidentais do círculo interno. Como consequência, professores e alunos reagiram a tal investida, usando a língua Tamil. Essa tentativa de imposição de uma língua a uma determinada comunidade é o que Canagarajah (2011) chamou de Imperialismo Linguístico. No entanto, o Sri Lanka conseguiu elaborar um contradiscurso e resistir a mais essa investida colonialista.

O princípio da Particularidade possibilita que de posse de informações locais, de um determinado grupo de aprendizes, a língua inglesa seja ensinada como língua global, numa perspectiva local, já que dados previamente colhidos podem orientar docentes quanto às necessidades reais de comunicação num viés local. Krachu (1992) ressalta, quanto a isso, o surgimento de formas locais do inglês, identificados e definidos através de suas estruturas distintivas gramaticais, lexicais, da pronúncia, do discurso e do estilo. Assim, é relevante, ao ensinar a língua inglesa, que docentes levem em consideração as particularidades de um 
determinado grupo de aprendizes, suas idiossincrasias, evitando, desse modo, uma série de insatisfações, enfretamento desnecessário e resultados insatisfatórios. Isso, obviamente, poderá ser evitado ao aproximar-se dos aprendizes e do contexto de aprendizagem, o que também possibilitará produzir conhecimento coerente com base na prática de aprendizagem, o que tem a ver com o próximo princípio que será descrito.

\subsection{PRINCÍPIO 2: DA PRATICIDADE}

Este princípio está assentado na noção de que para ter relevância local, qualquer conhecimento pedagógico deve emergir das práticas de ensino diárias. Assim, o cerne desse princípio constrói-se em torno da noção da inseparabilidade da Teoria e da Prática educativa, sinalizando a necessidade de o educador incorporar tanto o papel de educador quanto de produtor de teorias, para, desse modo, praticar com base em experiências pessoais. Nesse sentido, Kumaravadivelu (2012, p. 13) defende que:

O princípio da Praticidade objetiva romper a divisão de trabalho estabelecida entre o teorista e o professor, entre o produtor e o consumidor de conhecimento. Tal divisão artificial deixa muito pouco espaço para a autoconceituação e a autoconstrução do conhecimento pedagógico por parte do professor. É mais aparente que o conhecimento pedagógico, para ter qualquer relevância local, deve emergir de práticas de ensino cotidianas ${ }^{3}$.

A Praticidade possibilita a consolidação de uma prática educativo-crítica (FREIRE, 2010), capaz de propiciar atmosferas para reflexões que permitam educadores e aprendizes assumir-se como ser social e histórico, pensante, transformador e criador. Esse Teorizar/Praticar converge com os princípios da teoria educacional crítica (GIROUX, 1997), que traz em seu bojo a missão de desnudar as questões de dominação e opressão de diversos grupos sociais, por exemplo. Daí a necessidade do desenvolvimento da Praticidade, como princípio anti-tradicional, porque a educação tradicional, com suas teorias estáticas mirabolantes, pode alienar, limitar os indivíduos, bloqueando as suas ascensões. Já o princípio da Praticidade torna possível o aperfeiçoamento das práticas educativas e só poderá ser consolidado se docentes teorizarem com base nas suas práticas, o que, segundo Kumaravadivelu (2012), não pode ser feito simplesmente solicitando aos professores que coloquem em prática teorias alheias, porque como bem argumenta Freire (2010) 'é pensando criticamente a prática de hoje ou de ontem que se pode melhorar a próxima prática'. Na visão de Freire (2010), o elo entre Teoria e a Prática torna-se condição sine qua non para o desenvolvimento da reflexão crítica sobre a prática, cuja insensibilidade pode tornar a teoria um mero 'bla-bla-bla' e a prática um ativismo. Por isso a relevância da Praticidade, que tornará possível o desenvolvimento de uma prática investigativa, reflexiva, com a adoção de novas habilidades, atitudes e autonomia. Alinhado a isso, a Praticidade traz em seu bojo a compreensão e a transformação das possibilidades, tanto do professor quanto do aprendiz dentro e fora da sala de aula. A adoção desse princípio levará professores e aprendizes a 
uma atmosfera onde consigam dialogar e pensar o mundo fora da sala de aula. A Praticidade está profundamente relacionada com a Particularidade, porque é a partir do conhecimento de um determinado contexto de ensino/aprendizagem que se poderá obter dados para gerar teorias e essas mesmas teorias poderão servir de norte para práticas no mesmo contexto, e, quem sabe, vislumbrar alternativas viáveis de mudanças sociais, o que está diretamente relacionado com o próximo princípio que será descrito a seguir: o da Possibilidade.

\subsection{PRINCÍPIO 3: DA POSSIBILIDADE}

Este princípio centra-se nas concepções de educação defendidas por Paulo Freire. Essas concepções estão ancoradas em perspectivas pedagógicas críticas e conferem ao educador o caráter de ameaçador aos ditames impostos. Freire e seus seguidores acreditam que a Pedagogia Crítica é um meio de combater interesses escusos, que criam e mantém desigualdades sociais. Embora, muitas vezes, professores não encarem a sala de aula como arena para discussões de questões relevantes do mundo fora dela, as salas de aula são espaços sóciohistóricos e, como tal, podem através de uma Pedagogia Crítica empoderar aprendizes para criticamente se apropriarem do conhecimento, bem como podem possibilitar que professores e aprendizes contestem práticas de dominação ao usar a linguagem. (cf. KUMARAVADIVELU, 2012) Um ponto chave do Princípio da Possibilidade é que os professores precisam desenvolver teorias e práticas relevantes do ponto de vista individual e coletivo no contexto da sala de aula, fomentando a formação de identidades, porque a redefinição das identidades também é consolida quando transitamos no universo de outro idioma; por isso que 'quem aprende uma língua nova está se redefinindo como uma nova pessoa'. (RAJAGOPALAN, 2003)

Kumaravadivelu (2012) enfatiza que a Possibilidade traz em seu bojo o fato de que o uso da língua é um instrumento para o desenvolvimento de uma consciência sociocultural. Vejamos o que esse autor diz:

\footnotetext{
Dadas as demandas e expectativas do ambiente globalizado, educadores de professores de língua enfrentam a tarefa de ajudar professores e futuros professores a se tornarem conscientes de como eles são posicionados em vários contextos histórico, social e institucional e também das possibilidades e estratégias para transgredir as fronteiras artificiais que lhes são impostas por interesses escusos. (KUMARAVADIVELU, 2012, p. 15)
}

As fronteiras artificiais, as quais Kumaravadivelu (2012) faz menção parecem ser aquelas relacionadas com questões de conhecimento, poder e dominação, porque há uma ideologia nefasta que consegue legitimar de um lado as ideias das classes dominantes e, do outro, silenciar os oprimidos. Como isso se dá no ensino de língua inglesa? Quando, por exemplo, professores, autores e editores de livros didáticos corroboram uma pedagogia mercantilista (SCHEYERL, 2012), fomentam a divisão de mundos e práticas das culturas hegemônicas, sonegando informações locais, deixando de problematizar questões relevantes de interesse coletivo local. Mas o professor, com base na Pedagogia Crítica, age na contramão 
dessa ideologia, o que ele faz, na verdade, é estimular a visão crítica dos discentes, mediando a formação de uma postura crítica, questionadora de certezas e dogmas intocáveis. Por isso o educador crítico representa uma ameaça aos poderes constituídos. (RAJAGOPALAN, 2003) Daí a necessidade de conscientizar professores de línguas estrangeiras com relação ao princípio da Possibilidade, para que possam juntos com seus alunos confrontar criticamente ideologias impostas por grupos hegemônicos, com argumentos teóricos consistentes, construídos com base em suas próprias realidades, o que nada mais é que o princípio da Possibilidade.

$\mathrm{Na}$ seção seguinte discorro brevemente sobre a descolonização do conhecimento em língua inglesa, o que pode ser feito através da operacionalização dos princípios anteriormente esclarecidos.

\section{ENTENDER UMA LÍNGUA GLOBAL PARA DESCOLONIZAR O CONHECIMENTO}

Para ensinar uma língua global é preciso entender o seu caráter. É preciso compreender que se global, ela não se restringe mais às culturas hegemônicas. Um novo modelo de inglês emerge neste momento, o qual não está sendo aprendido como língua estrangeira, em reconhecimento ao poder dos falantes nativos das culturas hegemônicas. (GRADDOL, 2006) Se global, uma língua, obviamente, desatrela-se de suas origens e deve ser pensada em diversas perspectivas, e, assim, se promove a diversidade cultural e linguística. $\mathrm{O}$ acento é um dos fatores que devem ser levados em consideração quando se ensina uma língua global. Quanto a isso, por exemplo, Graddol (2006) defende que a falta do acento nativo não será visto como sinal de competência pobre e enfatiza que essa ideia de um aprendiz ter que adotar o acento nativo é uma das mais antiquadas sobre o ensino/aprendizagem do inglês.

Barcelos (2016) em seu artigo Finding My Own Voice and Accent ${ }^{4}$, fala da crença generalizada, no contexto brasileiro, de que se deve falar inglês com os acentos britânico e americano. Essa autora relata a sua própria experiência, como aprendiz da língua inglesa, destacando que, no imaginário popular brasileiro, falar o 'Brazilian English', equivale a falar um mau inglês ou não ter um inglês perfeito. Barcelos revela seus sentimentos iniciais por não conseguir alcançar a suposta perfeição linguística do falante nativo do inglês, o que a meu ver, ao deixá-la frustrada, envergonhada, configurou-se um sério complexo de inferioridade Esse complexo ocorre quando aprendizes sentem-se diminuídos em suas autoestimas (RAJAGOPALAN, 2003), por causa de práticas e posturas, notadamente equivocadas, que são adotadas em muitas salas de aulas de língua inglesa. Vejam o que ela nos relata:

Depois que conclui a graduação eu pude ver que essa crença estava em todo lugar, não apenas dentro de mim ou no ambiente universitário. Quando eu ouvia as pessoas falando sobre o inglês uma das outras eu pude ver que ter uma pronúncia nativa era muito valorizado. Você tem que soar diferente, você não deve soar como um brasileiro. Isso era vergonhoso. Muitas vezes eu me sentia envergonhada de falar na frente de outros falantes brasileiros do inglês por que eu tinha vergonha da minha pronúncia e de como eu 
falava. Eu sabia que muitos professores falavam melhor (mas o que é melhor nesse caso?) do que eu. Eu me sentia frustrada e sozinha. Eu não tentava soar diferente, e mais, eu sofria por que eu não soava como eles ${ }^{5}$. (BARCELOS, 2016, p. 2)

Barcelos superou essa frustração, abandonou as crenças, a partir da compreensão de que língua está intrinsecamente relacionada com identidade e, assim, descobriu que a manutenção da sua identidade de falante brasileira do inglês era essencial para marcar quem, de fato, era. No entanto, parece ainda povoar o imaginário popular a noção equivocada etnocêntrica de emulação dos acentos das culturas hegemônicas. Para desconstruir essa noção equivocada, precisamos compreender e praticar o ensino do inglês como língua global no Brasil e encerrar, quem sabe, de uma vez por todas, o ensino do inglês como língua estrangeira, porque já parece non sense e contribui para a manutenção de falácias que subestimam falantes não nativos do inglês e suas culturas, sobretudo quando a manutenção do acento brasileiro opera, e os próprios brasileiros sinalizam que não se fala um bom inglês.

Ultimamente tenho refletido sobre essa questão de ensinar uma língua global como estrangeira. Passei a ter sérias reservas ao termo 'língua estrangeira' para fazer referência à língua inglesa, embora já o tenha usado muito, porque acredito que tendo em vista o status que ela ocupa na contemporaneidade, podemos nos apropriar dela, descolonizá-la e desestrangeirizá-la. Assim, não cabe mais o termo LE, prefiro segunda língua, língua franca ou língua global, já que, de fato, ela pode ser. Essa visão traz como consequências implicações pedagógicas, porque provoca a descentralização do modelo do falante nativo. Isso automaticamente promove um cenário em que os aprendizes/falantes podem sinalizar as suas nacionalidades, e outros aspectos de suas identidades através do inglês (GRADDOL, 2006), sem o receio de serem rechaçados ou debochados, por usar a língua inglesa com aspectos das suas identidades, possibilitando, assim, descolonizar o conhecimento. Isso só acontecerá com o abandono de abordagens que privilegiam exclusivamente as culturas hegemônicas.

Tudo isso tem a ver com a descolonização do conhecimento, que também só ocorrerá quando docentes críticos e politizados se engajarem na desconstrução da visão eurocêntrica, etnocêntrica de mundo, o que tem, há anos, minimizado, colocado em posição de inferioridade povos e culturas, ao impor hábitos e costumes das culturas hegemônicas como superiores e avançadas. Isso prova, de algum modo, que o colonialismo também se deu na esfera epistemológica, alicerçando uma relação desigual de saber-poder que resultou na supressão de diversas formas idiossincráticas de muitos povos colonizados - o epistemicídio -, com o intuito de homogeneizar o mundo, pavimentando o caminho para a subalternidade. (SOUSA SANTOS, 2009)

É com a desconstrução do saber colonizado que docentes e aprendizes se desvencilharão, de fato, das artimanhas ideológicas coloniais. Essa desconstrução poderá ocorrer ancorada nos princípios explanados anteriormente e funcionará, perante a modernidade eurocêntrica, como uma resposta transmoderna descolonial (do subalterno), o que Mignolo (2000 apud GROSFOGUEL, 2009) 
convencionou chamar de 'pensamento crítico de fronteira', em busca da descolonização, a fim de superar a modernidade eurocêntrica.

\section{CONCLUINDO POR ENQUANTO...}

O status de língua global que a língua inglesa ora alcança requer um novo pensar sobre procedimentos metodológicos para o ensino/aprendizagem dessa língua. No mundo global, onde há encontro de povos e redefinição de identidades, não cabe uma unidade linguística (monocêntrica), mas uma diversidade linguística na unidade, e assim é possível falar no Brazilian English, no French English, no Italian English, no Chinglish (chinês + inglês), Spanglish (Espanhol + Inglês) e tantas outras variedades do inglês. Por isso, o inglês como língua franca global, é uma alternativa viável, quando na medida em que emerge como um novo modelo de inglês, abarca uma diversidade linguística dentro de si. E o seu reconhecimento como modelo a ser seguido nas escolas e universidades deve orientar a escolha metodológica (abordagem) adequada, o que consequentemente possibilitará a descolonização da língua inglesa.

Nesse sentido é que tenho defendido a descolonização do conhecimento em língua inglesa, em diversos níveis, fonológico, lexical e cultural, porque essa descolonização pode favorecer falantes de outras línguas, aqueles que aprendem o inglês como possível alternativa de comunicação, já que, desse modo, podem, com segurança e conforto, falar esse idioma, sem o receio de serem rechaçados, porque ela [a língua inglesa], já não mais estática e presa às normas hegemônicas, se faz global, a serviço de diversos falantes no mundo. Por isso mesmo não há necessidade (aliás, nunca teve) de submissão aos ditames das culturas hegemônicas de língua inglesa, afinal uma língua sem donos, global, que pertence a qualquer um que se proponha a usá-la, não requer que seja ensinada com base em tais ditames. Ao contrário, uma língua global, é multicultural por natureza, democrática, de identidades múltiplas. E para conduzir o ensino/aprendizagem de uma língua global, de fato, princípios norteadores são fundamentais. Eles possibilitarão que os professores ajam com autonomia. Daí a necessidade de conscientizar docentes com princípios consistentes que os conduzam a caminhos capazes de consolidar resultados significativos.

Vamos a busca de alternativas que extingam, de uma vez por todas, visões monocêntricas do inglês e defender a bandeira da democracia e da diversidade linguística. Assim, será possível a elaboração de um contradiscurso, o qual corroborará o ensino do inglês que capacite novos falantes a alcançar um padrão de compreensão e autoexpressão, que, inevitavelmente, será compreendido no mundo todo. 


\title{
Fundamental Tenets for the Teaching And Learning of English as a Global Language
}

\begin{abstract}
This paper aims at reflecting on the fundamental tenets for the teaching and learning of English as a global language. It seeks, in the postcolonial perspective and, in the light of the Applied Linguistics, to articulate the dialog with scholars (BOAVENTURA DE SOUSA SANTOS, 2009; PENNYCOOK, 2000; KUMARAVADIVELU, 2012; RAJAGOPALAN, 2003, 2009 and GROSFOGUEL, 2009), whose ideas converge to the decolonization of knowledge. Anchored in the Critical Pedagogy and taking into account the global status of the English language, this work paves the way for the discussion about problems which basic and higher education face, when they still relegate the teaching of English to a secondary plane, being at the mercy of fragile linguistics policies. The discussion soon is expanded, at last, to bring with it a proposal of decolonization of the English language, up adopting critical pedagogies which can make possible learner's emancipation, so that they can use this global language with autonomy and free of the colonialist ideologies moorings which limit thought and detract people and cultures, what might happen with usage of tenets which guide educators to the consolidation of meaningful learnings.
\end{abstract}

KEYWORDS: Teaching/learning. Tenets. Decolonization. English language. 


\section{NOTAS}

1 'Fins integrativo' diz respeito à intenção que um indivíduo qualquer tem de integrar-se a uma outra comunidade linguística, precisando, para tanto, dominar uma determinada língua.

${ }^{2}$ Do original: Having a global language has assisted globalization, and globalization has consolidated the global language. That process started with the dominance of two successive English-speaking empires, British and American, and continues today with the new virtual empire of the Internet.

${ }^{3}$ Tradução minha: The principle of practicality aims to break the established division of labor between the theorist and the teacher, between the producer and the consumer of knowledge. Such an artificial division leaves very little room for self-conceptualization and self -construction of pedagogic knowledge on the part of the teacher. It is rather apparent that pedagogic knowledge, to have any local relevance, must emerge from the practice of everyday teaching.

${ }^{4}$ Descobrindo a minha própria voz e o meu acento.

${ }^{5}$ Tradução minha: After I graduated I could see that this belief was everywhere, not only inside me or in the university environment. When you heard people talking about each other's English you could see that having a "native-like pronunciation" was very valued. You had to sound different, you could not sound Brazilian. That was seen as a shame. Many times I felt ashamed of speaking in front of other Brazilian speakers of English because I was ashamed of my pronunciation and of how I sounded. I knew many teachers sounded "better" (but what is better in this case?) than I did. I felt frustrated and lonely. I did not try to sound different, yet I suffered because I did not sound like "them.

\section{REFERÊNCIAS}

ANJOS, F. A. Ideologia e omissão nos livros didáticos de língua inglesa. Cruz das Almas: EdUFRB, 2017.

ANJOS, F. A. "Pra que aprender inglês se não vou para os Estados Unidos": Um estudo sobre atitudes de alguns alunos da escola pública em relação à aprendizagem do inglês como língua estrangeira. Dissertação de mestrado, 152 p. Mestrado em Língua e Cultura. Instituto de Letras, Universidade Federal da Bahia (UFBA), 2013.

ASSIS-PETERSON, A. A. de; COX, M. I. P. Inglês em tempos de globalização: para além de bem e mal. In: Calidoscópio, v. 5, n.1, p. 5-14, jan./abr. 2007.

BAGNO, M. A inevitável travessia: da prescrição gramatical à educação linguística. In: BAGNO, M; STUBBS, M.; GAGNÉ, G. (Org.) Língua materna: letramento, 
variação \& ensino. São Paulo: Parábola, 2002. p. 13-84.

BARCELLOS, A. M. F. Finding My Own Voice and Accent. 2016. Disponível em: http://www.hltmag.co.uk/jun08/sart03.rtf. Acesso em: 27 jun. 2016.

CANAGARAJAH, S.; BEN SAID. Linguistic Imperialism. In: Reasearch Gate. 2011. Disp. em: https://www.researchgate.net/publication/301820652 Acesso em 27/jul/2016.

COX, M. I. P.; ASSIS-PETERSON, A. A. de. O drama do ensino de inglês na escola pública brasileira. In: ASSIS-PETERSON, A. A. de. (Org.). Línguas estrangeiras: para além do método. Cuiabá, MT: EdUFMT, 2008, p. 19-54.

CRYSTAL, D. English as a global language. USA: Cambridge University Press, 2012.

FREIRE, P. Educação e mudança. São Paulo: Paz e Terra, 1979.

FREIRE, P. Pedagogia da autonomia - saberes necessários à pratica educativa. São Paulo: Paz e Terra, 2010.

FREIRE, P. Pedagogia do oprimido. 59. ed. Rio de Janeiro: Paz e Terra, 2015.

GRADDOL, D. English Next: Why global English may mean the end of English as a foreign language. The British Council. London: The English Company (UK) Ltda, 2006.

GIROUX, H. A. Os professores como intelectuais: rumo a uma pedagogia crítica da aprendizagem. Trad.: Daniel Bueno. Porto Alegre: Artmed, 1997.

GROSFOGUEL, R. Para descolonizar os estudos de economia política e os estudos pós-coloniais: transmodernidade, pensamento de fronteira e colonialidade global. In: SOUSA SANTOS, B.; MENESES, M. P. Epistemologias dos Sul. Coimbra: Edições Almedina, 2009. p. 383-417.

JENKINS, J. Current perspectives on teaching World English and English as a lingua franca. TESOL Quarterly, v. 40, n. 1, p. 157-181, 2006.

KRACHU, B. The other tongue: English across culture. 2nd. United States of 
America: University of Illinois Press, 1992.

LACOSTE, Y. Por uma abordagem geopolítica da difusão do inglês. In: LACOSTE, Y; RAJAGOPALAN, K. (Org.). A geopolítica do inglês. São Paulo: Parábola, 2005, p.711.

LE BRETON, J-M. Reflexões anglófilas sobre a geopolítica do inglês. In: LACOSTE, Y.; RAJAGOPALAN, K. (Org.). A geopolítica do inglês. São Paulo: Parábola, 2005, p.12-26.

MIDANS, S. Across cultures, English is the word. In: The New York Times, April, $2007 . \quad$ Disponível em: http <http://www.nytimes.com/2007/04/09/world/asia/09ihtenglede.1.5198685.html?_r=0>Acesso em 11/jul./2016.

MIGNOLO, W. Local Histories/Global Designs: Essays on the Coloniality of Power, Subaltern Knowledges and Border Thinking. Princeton: Princeton University Press, 2000.

MOITA LOPES, L. P. Oficina de linguística aplicada. Campinas, São Paulo: Mercado de Letras, 1996.

PENNYCOOK, A. English and the discourses of colonialism. London: Routledge, 1998.

PENNYCOOK, A. ELT and Colonialism. In: Research Gate, 2006.

RAJAGOPALAN, K. Por uma linguística crítica. Linguagem, identidade e a questão ética. São Paulo: Parábola, 2003.

RAJAGOPALAN, K. O inglês como língua internacional na prática docente. In: LIMA, D. C. de (Org.). Ensino e aprendizagem de língua inglesa. Conversas com especialistas. São Paulo: Parábola, 2009, p. 39-46.

RAJAGOPALAN, K. O lugar do inglês no mundo globalizado. In: SILVA, K. A. Ensinar e aprender línguas na contemporaneidade: linhas e entrelinhas. Campinas, SP: Pontes, 2010, p. 21-24.

RAJAGOPALAN, K. Vencer barreiras e emergir das adversidades com pleno êxito, sempre com o pé no chão. In: LIMA, D. C. de (Org.). Inglês em escolas públicas 
não funciona? Uma questão, múltiplos olhares. São Paulo: Parábola, 2011, p. 5565.

RICHARDS, J. C.; RODGERS, T. S. Approaches and Methods in Language Teaching. 3. rd. Cambridge University Press, 2014.

RICHARDS, J. C. The Changing Face of Language Learning: Learning Beyond the Classroom. RELC Journal, 2014, p. 1-18.

SCHEYERL, D.; SIQUEIRA, D. S. P. (Org.). Materiais didáticos para o ensino de línguas na contemporaneidade: contestações, proposições. Salvador: EdUFBA, 2012.

SCHMITZ, J. R. Um mundo globalizado, híbrido, pós-colonizado e pós-moderno: reflexões sobre o inglês na atualidade. Fólio: Revista de Letras. V. 8, n. 1. p. 333335, Vitória da Conquista, 2016.

SOUSA SANTOS, B.; MENESES, M. P. Epistemologias dos Sul. Coimbra: Edições Almedina, 2009. 
Recebido: 05 out. 2016

Aprovado: 07 ago. 2017

DOI: $10.3895 /$ rl.v12n24.2894

Como citar: ANJOS, Flavius Almeida dos. Princípios fundamentais para o ensino e a aprendizagem do Inglês como língua global. R. Letras, Curitiba, v. 19, n. 25, p. 114-132 jan./jun. 2017. Disponível em: $<$ https://periodicos.utfpr.edu.br/rl>. Acesso em: XXX.

Direito autoral: Este artigo está licenciado sob os termos da Licença Creative Commons-Atribuição 4.0 Internacional.

(c) (1) 